\title{
Association of menopausal symptoms with sociodemographic factors and personality traits
}

\author{
Areti Augoulea ${ }^{1}$, Michalis Moros ${ }^{1}$, Nikolaos Kokras ${ }^{2}$, Vasilios Karageorgiou ${ }^{1}$, Stavroula A. Paschou ${ }^{1}$, \\ Rallou Lymberi ${ }^{1}$, Konstantinos Panoulis ${ }^{1}$, George Kaparos ${ }^{1,3}$, Aikaterini Lykeridou ${ }^{4}$, Irene Lambrinoudaki ${ }^{1}$ \\ ${ }^{1}$ Second Department of Obstetrics and Gynecology, Medical School, National and Kapodistrian University of Athens, Athens, Greece \\ ${ }^{2}$ First Department of Psychiatry, Medical School, National and Kapodistrian University of Athens, Athens, Greece \\ ${ }^{3}$ Department of Biopathology, Aretaieio University Hospital, Athens, Greece \\ ${ }^{4}$ Department of Midwifery, University of West Attica, Athens, Greece
}

\section{Abstract}

Aim of the study: To investigate the association of personality traits with the severity of vasomotor symptoms (VMS) in a predominantly Greek population.

Material and methods: A questionnaire-based study of women from the Menopause Clinic of a University Hospital in Athens, Greece. Sociodemographic parameters were documented through a structured interview. All women completed the Menopause Rating Scale (MRS) for the assessment of severity of menopausal symptoms, the Hot Flush Beliefs Scale (HFBS) for the assessment of how women were coping with their symptoms and the Big Five Inventory questionnaires for the assessment of personality traits. Associations between baseline parameters and menopausal symptoms were assessed with univariate and multivariate regression analyses.

Results: One hundred women were included. Employed women had lower MRS sub-scores (psychological $p<0.001$, somatic $p<0.047$, urogenital $p<0.008$ ). Married women scored higher in the psychological and somatic domains. Women of university educational level coped significantly better with hot flushes ( $\beta$ coefficient [SE]: 0.72 [0.25], $p<0.01)$ and night sweats $(0.57$ [0.19], $p<0.01)$ than women of primary education, although the significance of these findings was not replicated when taking into account confounders. Regarding personality traits, women with low openness $(-0.33$ [0.11], $p<0.01)$ and empathy $(-0.83$ [0.37], $p=0.03)$ and high agreeableness $(1.13$ [0.21], $p<0.001)$ had more severe menopausal symptoms. In contrast, women with high agreeableness could better cope with their menopausal symptoms $(-0.75[0.36], p=0.04)$. These associations were independent of sociodemographic factors.

Conclusions: Personality traits, especially agreeableness, openness and empathy are associated with menopausal symptoms and functionality in postmenopausal women. These associations might serve as indicators of women at risk of experiencing more severe VMS.

Key words: personality, menopause, climacteric, symptoms, sociodemographic.

\section{Introduction}

Menopause represents the natural and permanent end of the woman's reproductive cycle, occurring at an average age of 51 years [1, 2]. Vasomotor symptoms (VMS), including hot flushes and night sweats, affect $60 \%$ to $70 \%$ of postmenopausal and up to $75 \%$ of perimenopausal women, exhibiting significant variability among different ethnic populations [3].

Hot flushes are the most typical menopausal symptoms, being a sudden feeling of heat originating from their face and chest, which gradually expands to the whole body and usually ends with sweating [4]. During this time, there is an increase in the cardiac rate and the skin becomes reddish and hot due to vasodilation. Before each incident, an increase in the basal temperature of the body is observed [4]. These episodes usually last between 3 and 10 minutes; they can happen at any time of the day and with any frequency [4].

Currently, there is no definitive explanation of the phenomenon, but it is thought to happen due to a decrease in the range of the thermoneutral zone of the hypothalamus [4]. Moderate to severe hot flushes showed a median duration of 10.2 years in a cohort of 259 women who were followed longitudinally for 13 years [5]. The authors noted a trend of lower VMS duration in 
women who experienced VMS onset at later stages of menopause [5]. In Greece, a recent study showed that almost 1 in 3 women who are in the transition phase or within 5 years after menopause experience moderate or severe vasomotor symptoms [6].

Various theories and hypotheses have tried to identify personality factors that may affect the occurrence of such symptoms. Personality refers to significant and relatively stable aspects of behavior or a series of behaviors, cognitions and emotional motifs deriving from both biological and environmental factors [7]. A contemporary and widely accepted theory nowadays is the theory of the "Big Five" characteristics of any personality: openness, conscientiousness, extraversion, agreeableness and neuroticism [8]. In order to measure and quantify the characteristics of the personality, several psychometric tools have been proposed. These are questionnaires that have been constructed in a way that ensures validity and reliability. Of course, there are several prerequisites that need to be met, in order to minimize possible effects of external factors.

The aim of this study was to assess the association of the severity of menopausal symptoms with personality traits and sociodemographic parameters in a sample of community dwelling postmenopausal women.

\section{Material and methods \\ Participants}

Postmenopausal women were consecutively recruited from the Menopause Clinic of the Aretaieio University Hospital in Athens, Greece, between January 2015 and December 2017. All women provided signed informed consent. Menopause was defined as a) amenorrhoea for at least 6 months and b) FSH $>25$ mIU and $\mathrm{E} 2<50 \mathrm{pg} / \mathrm{ml}$.

Exclusion criteria were: 1 ) presence of any chronic and serious disease affecting women's quality of life, 2) known psychopathology under psychiatric treatment, 3) administration of hypnagogic or psychotropic medication, 4) administration of hormone replacement therapy (HRT), 5) working in night shifts and 6) postmenopausal status $>10$ years. After application of the above exclusion criteria, 100 women participated in this study. All women provided written informed consent and the study was approved by the Ethics Committee of Aretaieio Hospital.

\section{Data collection}

Sociodemographic and medical history were taken from all women. Then, participants answered the following self-reporting questionnaires: 1) Menopause Rating Scale (MRS), 2) Hot Flush Beliefs Scale (HFBS), and 3) Big Five Inventory (BFI). The MRS is an 11-item questionnaire, which assesses the severity of climacteric symptoms on a 5 -point scale $(0=$ "not at all" to 4 = "extremely") [9]. The HFBS is a 27-item questionnaire which assesses the beliefs of participants about their hot flushes, based on a 6-point scale ( 1 = "totally agree" to 6 = "totally disagree"). The scale yields three categorical beliefs measures: coping with hot flushes, coping with night sweats and beliefs about the impact of the symptoms on women's social life. Higher score means worse coping with vasomotor symptoms [10]. The BFI is a psychometric tool, based on the Big Five model of personality. It is a 44-item questionnaire, which assesses the five principle aspects of personality (openness, conscientiousness, extraversion, agreeableness and neuroticism) on a 5-point scale (1 = "strongly disagree" to 5 = "strongly agree") [8]. Considering the location of residence, it was coded as urban and rural, where urban signified residence in a city with more than 10,000 registered citizens according to the 2011 census of the Hellenic Statistical Authority.

\section{Statistical analysis}

Data are presented as mean \pm standard deviation (SD) for continuous variables and as percentages (\%) for categorical variables. Normality was tested using the Shapiro-Wilk test. Results for which the null hypothesis of the Shapiro-Wilk test was rejected at the level of 0.05 , and thus were not likely to follow a normal distribution, were presented as median, range and interquartile range. Since normality of data is not a presupposition for regression analyses, univariate regression analysis was used for assessing the effect of personality sub-scores (openness, conscientiousness, empathy, agreeableness, neuroticism) on MRS and HFBS subscores and total scores. In addition, sociodemographic parameters (nationality, residence, occupation, marital status, educational level) were tested as independent variables for their effect on MRS and HFBS sub-scores and total scores (dependent variables). All research hypotheses were tested at the 0.05 significance level. The level of significance was set at $95 \%$ and discussion of the results was preferred to Bonferroni adjustment in order to avoid type II error inflation [11].

In order to thoroughly investigate the possible associations and their magnitude with regards to between-subject variation in potential confounding factors, an exploratory multiple regression model was performed. In an exploratory manner, variables that showed significance in the univariate analysis were included as independent covariables [12]. This analysis was performed only with MRS and HFBS total scores as dependent variables, in order to avoid the problem of multiple comparisons [13]. All statistical analyses were conducted using $\mathrm{R}$ version 3.5.1. 


\section{Results}

Demographic characteristics of the sample are presented in Table 1. The mean age of women included in the study was 52.1 years. The majority of them were Greek (86\%) and married (83\%), they were working (66\%, 34\% unemployed or retired) and had reached the education level of secondary school (42\%, 22\% primary school, 36\% university). Considering residence, $50 \%$ of the women lived in an urban environment and $50 \%$ lived in a village.

Since the null hypothesis of the measurements following the normal distribution could be safely rejected in most of the variables given the results of the Shapiro-Wilk test, results are presented as median, interquartile range $(\mathrm{IQR})$ and range. The median values of the BFI sub-scores were 2.75 for openness (range: 1.38-9, IQR: 0.87), 4.33 for conscientiousness (range: 2.78-5.33, IQR: 0.56), 3.965 for empathy (range: 2.11-4.89, IQR: 0.44), 3.062 for agreeableness (range: 1.5-4.63, IQR: 0.75) and 3.2 for neuroticism (range: 1.8-4.5, IQR: 0.525). Considering the MRS results, he median total score was 1.92 (range: 0.25-7.42, IQR: 0.94). The median HFBS total score was 11.1 (range: 6.96-18, IQR: 2.22).

\section{Univariate analysis}

In univariate analysis (Table 2), women with a lower openness score had significantly more severe psycho-
Table 1. Demographic characteristics of the postmenopausal women participating in the study $(n=100)$

\begin{tabular}{llll}
\hline $\begin{array}{l}\text { Demographic } \\
\text { characteristics }\end{array}$ & $n$ & $\begin{array}{c}\text { Frequency } \\
\text { (\%) }\end{array}$ & Mean \pm SD \\
\hline Age & & & $52.1 \pm 4.7$ \\
\hline Years from menopause & & & $3.8 \pm 2.9$ \\
\hline Nationality & 86 & 86 & \\
\hline Greek & 14 & 14 & \\
\hline Other & & & \\
\hline Residence & 50 & 50 & \\
\hline City & 50 & 50 & \\
\hline Village & & & \\
\hline Occupation & 66 & 66 & \\
\hline Working & 34 & 34 & \\
\hline Unemployed/retired & & & \\
\hline Marital status & 83 & 83 \\
\hline Married & 17 & 17 \\
\hline Divorced/single & & & \\
\hline Educational level & 22 & 22 \\
\hline Primary school & 42 & 42 \\
\hline Secondary school & 36 & 36 \\
\hline University & & \\
\hline
\end{tabular}

Table 2. Univariate linear regression analysis of the association of personality traits and sociodemographic parameters with MRS scores

\begin{tabular}{|c|c|c|c|c|}
\hline Parameter & MRS psychological & MRS somatic & MRS urogenital & MRS total \\
\hline BFI openness & $-0.23(0.05)^{\star \star \star \star}$ & $-0.147(0.05)^{\star *}$ & $-0.13(0.05)^{\star *}$ & $-0.507(0.12)^{\star \star \star}$ \\
\hline BFI conscientiousness & $0.21(0.14)$ & $-0.06(0.12)$ & $0.36(0.11)^{\star *}$ & $0.51(0.31)$ \\
\hline BFI empathy & $-0.14(0.14)$ & $-0.187(0.12)$ & $-0.063(0.11)$ & $-0.387(0.30)$ \\
\hline BFI agreeableness & $0.61(0.10)^{\star \star \star}$ & $0.54(0.09)^{\star \star \star}$ & $0.29(0.09)^{\star *}$ & $1.43(0.22)^{\star \star \star}$ \\
\hline BFI neuroticism & $-0.05(0.14)$ & $-0.12(0.12)$ & $-0.13(0.11)$ & $-0.30(0.31)$ \\
\hline \multicolumn{5}{|l|}{ Nationality } \\
\hline Greek & Reference & & & \\
\hline Other & $-0.47(0.19)^{*}$ & $-0.17(0.17)$ & $-0.40(0.16)^{\star}$ & $-1.04(0.43)^{*}$ \\
\hline \multicolumn{5}{|l|}{ Residence } \\
\hline City & Reference & & & \\
\hline Village/other & $-0.13(0.14)$ & $0.05(0.12)$ & $-0.08(0.11)$ & $-0.16(0.30)$ \\
\hline \multicolumn{5}{|l|}{ Occupation } \\
\hline Employed & Reference & & & \\
\hline Unemployed/retired & $0.49(0.13)^{\star \star \star}$ & $0.25(0.12)^{*}$ & $0.314(0.115)^{\star *}$ & $1.05(0.3)^{\star \star \star}$ \\
\hline \multicolumn{5}{|l|}{ Marital status } \\
\hline Married & Reference & & & \\
\hline Other & $-0.48(0.17)^{\star *}$ & $-0.34(0.15)^{\star}$ & $-0.21(0.15)$ & $-1.03(0.39)^{\star *}$ \\
\hline \multicolumn{5}{|l|}{ Educational level } \\
\hline Primary school & Reference & & & \\
\hline Secondary school & $0.3(0.18)$ & $0.24(0.15)$ & $0.28(0.14)$ & $0.83(0.39)^{*}$ \\
\hline University & $0.09(0.18)$ & $-0.09(0.16)$ & $-0.10(0.15)$ & $-0.09(0.39)$ \\
\hline
\end{tabular}

Data presented as $\beta$ coefficient (SE), BFI - Big Five Inventory, MRS - Menopause Rating Scale, ${ }^{*} p<0.05,{ }^{* *} p<0.01,{ }^{* * *} p<0.001$ 
logical (coefficient [SE]: -0.23 [0.05], $p<0.001$ ), somatic $(-0.15$ [0.05], $p<0.01)$ and urogenital $(-0.13$ [0.05], $p<0.01)$ symptoms as self-rated in the MRS subscores, as well as a higher MRS total score $(-0.51$ [0.31], $p<0.001)$. A higher agreeableness score was also associated with increased severity in these domains ( $p<0.001, p<0.01$ for urogenital symptoms). It was also noted that unemployed or retired status was significantly associated with an increased score in all domains. Married women also tended to score significantly higher in the psychological $(-0.48$ [0.17], $p<0.01)$ and somatic $(-0.34$ [0.15], $p<0.05)$ sub-scores, as well as in the total score $(-1.03$ [0.39], $p<0.01)$.

Considering the results of the HFBS questionnaire (Table 3), the sub-score that examined the beliefs about the self in a social context was most affected by between-subject differences in personality traits. Higher scores in openness $(0.22$ [0.08], $p<0.01)$, conscientiousness (0.53 [0.19], $p<0.01)$, empathy (0.68 [0.18], $p<0.001)$ and neuroticism (0.54 [0.18], $p<0.01)$ and lower scores in agreeableness $(-0.52$ [0.15], $p<0.01)$ were all significantly associated with a higher score, as well as the total HFBS score. Significantly different scores were also observed in HFBS sub-scores regarding beliefs about self in a social context and coping with hot flushes in women of varying educational levels $(0.38$ [0.12], $p<0.01$ and 0.31 [0.09], $p<0.01$ respectively). Women with higher scores in the neuroticism domain scored higher in the sub-score that assessed how women cope with hot flushes $(p<0.05)$, while a higher empathy score correlated with the self-reported coping of night sweats $(p<0.05)$ (Table 3). Considering demographic parameters, Greek nationality and urban residence correlated with higher scores considering beliefs in a social context (both $p<0.01$ ) as well as total score.

\section{Multivariate analysis}

Ten variables (openness, conscientiousness, empathy, agreeableness, neuroticism, education level, nationality, marital status, occupation and residence) were chosen as covariates in the analysis. These variables were chosen on the basis of having shown significance in at least one domain in the univariate analyses (Tables 2 and 3). Considering the results for the predictors of MRS total score, agreeableness (1.13 [0.21], $p<0.001)$, openness $(-0.33$ [0.11], $p=0.004)$ and extraversion $(-0.83$ [0.37], $p=0.03)$ demonstrated significance (Table 4), while conscientiousness was marginally non-significant $(p=0.06)$. In the HFBS to-

Table 3. Univariate linear regression analysis for the association of personality traits and sociodemographic parameters with HFBS scores

\begin{tabular}{|c|c|c|c|c|}
\hline Parameter & $\begin{array}{l}\text { HFBS coping with hot } \\
\text { flushes }\end{array}$ & $\begin{array}{l}\text { HFBS coping with night } \\
\text { sweats }\end{array}$ & $\begin{array}{l}\text { HFBS impact on social } \\
\text { life }\end{array}$ & HFBS total \\
\hline BFI openness & $-0.22(0.08)^{\star *}$ & $0.06(0.06)$ & $0.11(0.11)$ & $0.39(0.18)^{\star}$ \\
\hline BFI conscientiousness & $0.53(0.19)^{* \star}$ & $0.06(0.15)$ & $0.46(0.25)$ & $1.04(0.417)^{\star}$ \\
\hline BFI empathy & $0.68(0.18)^{* \star \star}$ & $0.18(0.15)$ & $0.53(0.25)^{\star}$ & $1.39(0.40)^{\star * \star}$ \\
\hline BFI agreeableness & $-0.52(0.15)^{\star *}$ & $-0.06(0.13)$ & $-0.32(0.21)$ & $-0.90(0.35)^{*}$ \\
\hline BFI neuroticism & $0.54(0.18)$ & $0.32(0.15)^{\star}$ & $0.25(0.26)$ & $1.11(0.41)^{\star \star}$ \\
\hline \multicolumn{5}{|l|}{ Nationality } \\
\hline Greek & Reference & & & \\
\hline Other & $-0.80(0.26)^{\star *}$ & $-0.23(0.21)$ & $-0.60(0.36)$ & $-1.63(0.59)^{* *}$ \\
\hline \multicolumn{5}{|l|}{ Residence } \\
\hline City & Reference & & & \\
\hline Village/other & $-0.59(0.18)^{\star *}$ & $-0.27(0.15)$ & $-0.10(0.25)$ & $-0.96(0.41)^{*}$ \\
\hline \multicolumn{5}{|l|}{ Occupation } \\
\hline Employed & Reference & & & \\
\hline Unemployed/retired & $-0.17(0.2)$ & $0.06(0.16)$ & $-0.17(0.27)$ & $-0.28(0.44)$ \\
\hline \multicolumn{5}{|l|}{ Marital status } \\
\hline Married & Reference & & & \\
\hline Other & $-0.14(0.25)$ & $0.11(0.20)$ & $0.03(0.34)$ & $0.005(0.56)$ \\
\hline \multicolumn{5}{|l|}{ Educational level } \\
\hline Primary school & Reference & & & \\
\hline Secondary school & $0.2(0.24)$ & $0.01(0.18)$ & $0.61(0.33)$ & $0.82(0.53)$ \\
\hline University & $0.72(0.25)^{\star \star}$ & $0.57(0.19)^{\star \star}$ & $-0.45(0.34)$ & $1.73(0.55)^{\star \star}$ \\
\hline
\end{tabular}


tal score analysis, only agreeableness was a marginal- Table 4. Multivariate linear regression analysis with MRS and ly significant predictor for a higher score $(-0.75$ [0.35], HFBS total scores as dependent variables and personality traits $p=0.04)$ (Table 4).

\section{Discussion}

This study provided evidence that, apart from the widely accepted impact of biological and endocrine factors, individual personality characteristics are associated with menopausal symptoms. Namely, introverted women with low empathy had more severe menopausal symptoms. Furthermore, women with high agreeableness, although they had higher scores on the menopausal rating scale, were better able to cope with their symptoms. These associations were independent of sociodemographic parameters.

Cultural factors have been shown to affect women's perception of VMS [14]. In our study, 14 women were of East European and Asian origin; hence inferences cannot be robust. In some societies, such as those of East Asia, menopause is not considered a negative event and VMS seem to be less intense. These differences in severity and frequency of VMS among different ethnic groups has resulted in the term "local biologies" being used in order to describe this cross-cultural heterogeneity [15]. Apart from ethnicity, occupational status may also affect the occurrence of VMS. A meta-analysis by Schoenaker et al. with participants from all continents has shown a significant association between occupation and the extent of VMS [16]. Still, the exact reason why occupational status affects the severity of VMS remains unclear. Probably social, psychological and other factors, such as lifestyle and eating habits, contribute through complex pathways [17]. Unemployment has been correlated with increased morbidity and mortality rates in the general population, whereas employment improves health indicators and is correlated with lower depression incidence in perimenopausal and postmenopausal women [18].

As far as marital status is concerned, evidence from previous studies suggests that marriage or a committed relationship has a modest protective effect on the perceived severity of menopausal symptoms [17]. However, married women from our study were found to experience more psychological and somatic symptoms. This difference may be attributed to other factors, such as specific characteristics of the relationship between partners, and could be probably explained within the socioeconomic and cultural environment of the specific population.

Regarding education, the results of our study suggest that educational level influences the women's severity and perception of their VMS. Secondary school graduates reported more somatic and urogenital symptoms compared with both primary school graduates and university degree holders. In addition, the linear regression analysis indicated a significant effect of education level on both MRS and HFBS total scores. Similar results have been demonstrated by previous studies [19]. and sociodemographic parameters as independent variables

\begin{tabular}{|c|c|c|c|c|}
\hline Parameter/variable & Estimate & SE & $T$ value & $p$-value \\
\hline \multicolumn{5}{|l|}{ MRS total score } \\
\hline Age & 0.02 & 0.04 & 0.67 & 0.51 \\
\hline \multicolumn{5}{|l|}{ Nationality } \\
\hline Greek & \multicolumn{4}{|c|}{ Reference } \\
\hline Other & -0.56 & 0.53 & -1.06 & 0.29 \\
\hline \multicolumn{5}{|l|}{ Residence } \\
\hline City & \multicolumn{4}{|c|}{ Reference } \\
\hline Village/other & -0.87 & 0.64 & -1.37 & 0.17 \\
\hline \multicolumn{5}{|l|}{ Marital status } \\
\hline Married & \multicolumn{4}{|c|}{ Reference } \\
\hline Other & -0.57 & 0.36 & -1.56 & 0.12 \\
\hline \multicolumn{5}{|l|}{ Education } \\
\hline Primary school & \multicolumn{4}{|c|}{ Reference } \\
\hline Secondary school & 0.47 & 0.36 & 1.30 & 0.2 \\
\hline University & -0.58 & 0.39 & -1.48 & 0.14 \\
\hline \multicolumn{5}{|l|}{ Occupation } \\
\hline Employed & \multicolumn{4}{|c|}{ Reference } \\
\hline Other & -0.12 & 0.29 & -0.40 & 0.69 \\
\hline Years in menopause & -0.05 & 0.04 & -1.18 & 0.24 \\
\hline BFI-openness & -0.33 & 0.11 & -2.97 & 0.004 \\
\hline BFl-conscientiousness & 0.67 & 0.36 & 1.88 & 0.06 \\
\hline BFl-empathy & -0.83 & 0.37 & -2.23 & 0.03 \\
\hline BFI-agreeableness & 1.13 & 0.21 & 5.52 & $<0.001$ \\
\hline BFI-neuroticism & 0.47 & 0.29 & 1.63 & 0.11 \\
\hline \multicolumn{5}{|l|}{ HFBS total score } \\
\hline Age & 0.03 & 0.05 & 0.65 & 0.52 \\
\hline \multicolumn{5}{|l|}{ Nationality } \\
\hline Greek & \multicolumn{4}{|c|}{ Reference } \\
\hline Other & -0.68 & 0.89 & -0.77 & 0.45 \\
\hline \multicolumn{5}{|l|}{ Residence } \\
\hline City & \multicolumn{4}{|c|}{ Reference } \\
\hline Village/other & -0.48 & 0.45 & -1.07 & 0.29 \\
\hline \multicolumn{5}{|l|}{ Marital status } \\
\hline Married & \multicolumn{4}{|c|}{ Reference } \\
\hline Other & 0.70 & 0.61 & 1.15 & 0.25 \\
\hline \multicolumn{5}{|l|}{ Educational level } \\
\hline Primary school & \multicolumn{4}{|c|}{ Reference } \\
\hline Secondary school & 0.50 & 0.64 & 0.78 & 0.44 \\
\hline University & 0.89 & 0.71 & 1.26 & 0.21 \\
\hline \multicolumn{5}{|l|}{ Occupation } \\
\hline Employed & \multicolumn{4}{|c|}{ Reference } \\
\hline Unemployed/retired & -0.02 & 0.49 & -0.03 & 0.97 \\
\hline BFI-openness & 0.19 & 0.20 & 0.98 & 0.33 \\
\hline BFl-conscientiousness & 0.37 & 0.61 & 0.61 & 0.55 \\
\hline BFl-empathy & 0.43 & 0.59 & 0.77 & 0.46 \\
\hline BFI-agreeableness & -0.75 & 0.36 & -2.12 & 0.04 \\
\hline BFI-neuroticism & 0.61 & 0.49 & 1.24 & 0.22 \\
\hline
\end{tabular}


Residence was not found to be a significant predictor for the intensity of VMS, as women living in urban areas reported slightly higher severity of psychological and urogenital symptoms, but slightly lower somatic symptoms compared with those living in rural areas. In the multiple regression analysis, however, it was found that urban living may potentially influence the subjective experience of VMS as this is manifested in the HFBS score. Most previous studies indicate that women in rural areas experience fewer menopausal symptoms than those living in urban areas [20], but other studies are not in the same line [21]. In general, evidence suggests that residence is an influential factor for menopausal symptoms $[22,23]$. However, this observation should be interpreted in the context of health-related quality of life, which is also affected by availability and accessibility to health services. The association of ethnic background with the prevalence and severity of vasomotor symptoms seem to also affect the differences between urban and rural populations [24].

Regarding personality traits, openness, empathy and agreeableness were the most important predictors for the intensity of menopausal symptoms in our study. In general, higher levels of extraversion and openness are correlated with better ability to adjust to social, cognitive and physical functioning across the lifespan [25], whereas personality has an important role in health-related quality of life [26]. Previous studies [27, 28] have also shown that higher frequency of vasomotor symptoms is correlated with lower scores of extraversion. Our results are also in accordance with the findings of Jurczak et al. [29], who also noted an elevated risk for more intense VMS symptomatology in women with low openness and extroversion.

Women with a high score in agreeableness showed better coping with menopausal symptoms, independently of sociodemographic parameters. In accordance to our results, Wieder-Huszla et al. [30] found that women with high agreeableness scored higher in all domains of the quality of life questionnaire SF-36, including general health and social functioning. Likewise, Bosworth et al. [31] demonstrated that midlife women with high agreeableness were less likely to rate menopause as a stressful event. Finally, in the study of Sassoon et al. [32] perimenopausal women with insomnia had lower scores in agreeableness compared to women without this symptom.

The strengths of this study include the strict criteria of inclusion and detailed record of demographic and medical data, as well as data deriving from structured examinations by trained specialists.

Limitations of our study include the small sample size, as well as the fact that all parameters assessed were self-reported and inconsistencies are possible. Although women did not report any psychiatric illness, no structured psychiatric interview was performed in order to assess the presence of depression or anxiety disorders. In addition, mean scores were low, with relatively small variation, and thus conclusions about the frank clinical severity of VMS in women of different personality types cannot be safely drawn. Cross-cultural differences also could not be meaningfully interpreted on a nationality level, given the low percentage of non-Greek women. Furthermore, the Menopause Clinic of our Department is a referral center; hence participants were less likely to reflect the general population (selection bias).

Recent studies report that women with moderate to severe vasomotor symptoms are at higher risk of developing cardiovascular disease compared to women without or with mild vasomotor symptoms [33]. These symptoms are associated with sociodemographic factors as well as with personality traits [34]. The results of our study indicate that some women with certain personality traits experience more bothersome climacteric symptoms compared to women without these traits. A personality assessment, therefore, may offer in the clinical setting a valuable tool to select women at risk of developing severe climacteric symptoms and offer them psychological support.

\section{Conclusions}

The present study provides evidence that sociodemographic parameters and personality traits of women in menopause are associated with the severity of VMS and the ability to cope with VMS. Women who are reserved and introvert experience more severe menopausal symptoms, while women with high agreeableness are better able to cope with their symptoms. If the causality of these associations is proven, our findings may aid the clinical assessment of women during the menopausal transition by identifying personality traits which increase the severity of menopausal symptoms. Future clinical studies should investigate the effect of personality traits on other important clinical outcomes, such as the duration of VMS, response to treatment and time to remission.

\section{Disclosure}

The authors report no conflict of interest.

\section{References}

1. Gold EB. The timing of the age at which natural menopause occurs. Obstet Gynecol Clin North Am 2011; 38: 425-440.

2. Adamopoulos DA, Karamertzanis M, Thomopoulos A, et al. Age at menopause and prevalence of its different types in contemporary Greek women. Menopause 2002; 9: 443-448.

3. Freeman EW, Sherif K. Prevalence of hot flushes and night sweats around the world: a systematic review. Climacteric 2007; 10: 197-214.

4. Freedman RR. Menopausal hot flashes: mechanisms, endocrinology, treatment. J Steroid Biochem Mol Biol 2014; 142: 115-120.

5. Freeman EW, Sammel MD, Lin H, et al. Duration of menopausal hot flushes and associated risk factors. Obstet Gynecol 2011; 117: 1095-1104. 
6. Grigoriou V, Augoulea A, Armeni E, et al. Prevalence of vasomotor, psychological, psychosomatic and sexual symptoms in perimenopausal and recently postmenopausal Greek women: association with demographic, life-style and hormonal factors. Gynecol Endocrinol 2013; 29: 125-128.

7. Hampson SE. Personality processes: mechanisms by which personality traits "get outside the skin". Annu Rev Psychol 2012; 63: 315-339.

8. Lang FR, John D, Lüdtke O, et al. Short assessment of the Big Five: robust across survey methods except telephone interviewing. Behav Res Methods 2011; 43: 548-567.

9. Heinemann K, Ruebig A, Potthoff P, et al. The Menopause Rating Scale (MRS) scale: a methodological review. Health Qual Life Outcomes 2004 2: 45 .

10. Rendall MJ, Simonds LM, Hunter MS. The Hot Flush Beliefs Scale: a too for assessing thoughts and beliefs associated with the experience of menopausal hot flushes and night sweats. Maturitas 2008; 60: 158-169.

11. Perneger TV. What's wrong with Bonferroni adjustments. BMJ 1998; 316: 1236-1238.

12. Alexopoulos EC. Introduction to multivariate regression analysis. Hippokratia 2010; 14 (Suppl 1): 23-28.

13. Feise RJ. Do multiple outcome measures require $p$-value adjustment? BMC Med Res Methodol 2002; 2: 8 .

14. Melby MK, Lock M, Kaufert P. Culture and symptom reporting at menopause. Hum Reprod Update 2005; 11: 495-512.

15. Lock M, Kaufert P. Menopause, local biologies, and cultures of aging. Am J Hum Biol 2001; 13: 494-504.

16. Schoenaker DA, Jackson CA, Rowlands JV, Mishra GD. Socioeconomic position, lifestyle factors and age at natural menopause: a systematic review and meta-analyses of studies across six continents. Int J Epidemiol 2014; 43: 1542-1562.

17. Lee MS, Kim JH, Park MS, et al. Factors influencing the severity of menopause symptoms in Korean post-menopausal women. J Korean Med Sc 2010; 25: 758-765.

18. Artazcoz L, Benach J, Borrell C, Cortès I. Unemployment and mental health: understanding the interactions among gender, family roles, and social class. Am J Public Health 2004; 94: 82-88.

19. Forouhari S, Khajehei M, Moattari M, et al. The Effect of Education and Awareness on the Quality-of-Life in Postmenopausal Women. Indian J Community Med 2010; 35: 109-114.

20. Martinez JA, Palacios S, Chavida F, Perez M. Urban-rural differences in Spanish menopausal women. Rural Remote Health 2013; 13: 1865.

21. Bojar I, Lyubinets O, Novotny J, et al., Intensification of menopausal symptoms among female inhabitants of East European countries. Ann Agric Environ Med 2016; 23: 517-524.

22. Keenan NL, Mark S, Fugh-Berman A, et al. Severity of menopausal symptoms and use of both conventional and complementary/alternative therapies. Menopause 2003; 10: 507-515.

23. Lan $\mathrm{Y}$, Huang $\mathrm{Y}$, Song $\mathrm{Y}$, et al. Prevalence, severity, and associated factors of menopausal symptoms in middle-aged Chinese women: a community-based cross-sectional study in southeast China. Menopause 2017 24: 1200-1207.

24. Im EO, Lee B, Chee W, et al. Menopausal symptoms among four major ethnic groups in the United States. West J Nurs Res 2010; 32: 540-565.

25. Stephan Y, Boiché J, Canada B, Terracciano A. Association of personality with physical, social, and mental activities across the lifespan: Findings from US and French samples. Br J Psychol 2014; 105: 564-580.

26. Chapman BP, Roberts B, Duberstein P. Personality and longevity: knowns, unknowns, and implications for public health and personalized medicine. J Aging Res 2011; 2011: 759170.

27. Brown JP, Gallicchio L, Flaws JF, Tracy JK. Relations among menopausal symptoms, sleep disturbance and depressive symptoms in midlife. Maturitas 2009; 62: 184-189.

28. Elavsky S, McAuley E. Personality, Menopausal Symptoms, and Physica Activity Outcomes in Middle-Aged Women. Pers Individ Dif 2009; 46 123-128.

29. Jurczak A, Szkup M, Wieder-Huszla S, et al. The assessment of the relationship between personality, the presence of the $5 \mathrm{HTT}$ and MAOA polymorphisms, and the severity of climacteric and depressive symptoms in postmenopausal women. Arch Womens Ment Health 2015; 18 : 613-621.
30. Wieder-Huszla S, Szkup M, Jurczak A, et al. Effects of socio-demographic, personality and medical factors on quality of life of postmenopausal women. Int J Environ Res Public Health 2014; 11: 6692-6708.

31. Bosworth HB, Bastian LA, Rimer BK, Siegler IC. Coping styles and personality domains related to menopausal stress. Womens Health Issues 2003; 13: 32-38.

32. Sassoon SA, de Zambotti M, Colrain IM, Baker FC. Association between personality traits and DSM-IV diagnosis of insomnia in peri- and postmenopausal women. Menopause 2014; 21: 602-611.

33. Savonitto S, Ferri LA, Colombo D. Perimenopause vasomotor symptoms, coronary atherosclerosis and risk of myocardial infarction during menopause: the cardiologist's perspective. Prz Menopauzalny 2018; 17: 53-56.

34. Augoulea A, Moros M, Lykeridou A, et al. Psychosomatic and vasomotor symptom changes during transition to menopause. Prz Menopauzalny 2019; 18: 110-115. 